\title{
Kajian Pengerukan Waduk Sengguruh Kepanjen Kabupaten Malang
}

\author{
Ir. Endro Yuwono, MT \\ Muhammad Sabaruddin, ST \\ Teknik Sipil \\ Institut Teknologi Nasional Malang \\ Jl. Sigura-gura no 1 Malang \\ Email: end1968yuwono@gmail.com
}

\begin{abstract}
Sengguruh dam located between $07^{\circ} 44^{\prime} 20^{\prime \prime}-08^{\circ} 17^{\prime} 45^{\prime \prime}$ latitude and $112^{\circ} 27^{\prime} 30^{\circ}-112^{\circ} 57^{\prime} 55^{\circ} \mathrm{E}$ Longitude, Village Sengguruh, Kepanjen, Malang, East Java Province. The total volume of reservoir dam Sengguruh as much as 21.5 million $\mathrm{m}^{3} \pm 2.5$ million $\mathrm{m}^{3}$ and \pm 19 million $\mathrm{m}^{3}$ sediment trap. Sengguruh dam gets water supply from the Brantas River and Lesti River, both of them are components of the Brantas upstream water sheet with monthly average discharge $55.2 \mathrm{m3} / \mathrm{s}$ and 2,065 mm of rainfall. Garbage in Sengguruh Dam reached $30 \mathrm{~m}^{3} /$ day and it is increased to $200 \mathrm{m3} /$ day during the rainy season. Average yearly total garbage and sediment reaching 5 million $\mathrm{m}^{3}$, meanwhile technical ability and sediment scavenge only about 300 thousand $\mathrm{m} 3$ / yr. Limitations of equipment and container land sediments become an obstacle. The rest, settle down and become disturbing waste dam. Hence it cause production of hydroelectric power (hydropower) decreased from $29 \mathrm{MW} /$ day to $18 \mathrm{MW} /$ day. So that the to normalize function of reservoir need dredging, dredging effort in order to be effective required a proper plan by analyzing sediment, dredging equipment used, cost analysis and how much impact if the reservoir Sengguruh dredged to increase hydroelectric power production when viewed in terms of its economy.
\end{abstract}

Keywords: Reservoir, sediment

\begin{abstract}
Abstrak

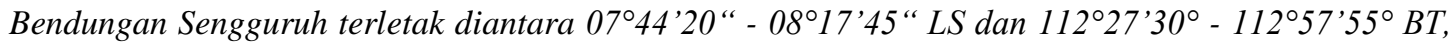
Desa Sengguruh, Kepanjen, Kabupaten Malang, Propinsi Jawa Timur. Total volume tampungan Bendungan Sengguruh sebanyak 21,5 juta $\mathrm{m}^{3}$ dengan rincian $\pm 2,5$ juta $\mathrm{m}^{3}$ volume efektif dan \pm 19 juta $\mathrm{m}^{3}$ tampungan volume sedimen. Bendungan Sengguruh mendapat pasokan air dari Sungai Brantas dan Sungai Lesti yang keduanya merupakan komponen hulu dari DAS Brantas dengan debit rata-rata bulanan $55,2 \mathrm{~m}^{3} / \mathrm{s}$ dan curah hujan 2,065 mm. Sampah di Bendungan Sengguruh mencapai $30 \mathrm{~m}^{3} / \mathrm{hr}$ dan sampah meningkat menjadi $200 \mathrm{~m}^{3} / \mathrm{hr}$ hari saat musim hujan. Rata-rata tiap tahun total sampah dan sedimen mencapai 5 juta $\mathrm{m}^{3}$ sedangkan kemampuan teknis mengeruk sampah dan sedimen hanya sekitar $300 \mathrm{ribu} \mathrm{m}^{3} / \mathrm{th}$. Keterbatasan peralatan dan lahan penampung sedimen menjadi penghambat. Selebihnya, sampah mengendap dan mengganggu bendungan. Dampaknya, produksi pembangkit listrik tenaga air (PLTA) menurun dari $29 \mathrm{MW} / \mathrm{hr}$ menjadi $18 \mathrm{MW} / \mathrm{hr}$. Agar waduk bisa berfungsi normal perlu adanya pengerukan, agar upaya pengerukan berjalan efektif diperlukan rencana yang tepat dengan menganalisa sedimen, alat keruk yang dipakai, analisa biaya serta seberapa besar dampaknya bila waduk Sengguruh dikeruk untuk meningkatkan produksi listrik tenaga air bila ditinjau dari segi ekonominya.
\end{abstract}

Kata Kunci : Waduk, sedimen 


\section{Pendahuluan}

\section{Latar Belakang}

Bendungan Sengguruh terletak di Desa Sengguruh, Kepanjen, Kabupaten Malang, Propinsi Jawa Timur. Total volume tampungan Bendungan Sengguruh sebanyak 21,5 juta $\mathrm{m}^{3}$, dengan rincian $\pm 2,5$ juta $\mathrm{m}$ sebagai volume efektif dan \pm 19 juta $\mathrm{m}$ sebagai tampungan volume sedimen. Bendungan Sengguruh mendapat pasokan air dari Sungai Brantas dan Sungai Lesti yang keduanya merupakan komponen hulu dari DAS Brantas dengan debit rata-rata bulanan $55,2 \mathrm{~m}^{3} / \mathrm{s}$ dan curah hujan 2,065 mm. Sampah di Bendungan Sengguruh mencapai $30 \mathrm{~m}^{3} /$ hari. Bahkan saat musim hujan sampah meningkat menjadi $200 \mathrm{~m}^{3}$ / hari ( PT Jasa Tirta). Rata-rata setiap tahun total sampah dan Sedimen mencapai lima juta $\mathrm{m}^{3}$. Sedangkan kemampuan teknis mengeruk sampah dan Sedimen hanya sekitar 300 ribu $\mathrm{m}^{3 /}$ tahun. Dampaknya, produksi pembangkit listrik tenaga air (PLTA) menurun dari 29 MW turun menjadi 18 MW /hari

\section{Rumusan Masalah}

Berapa jumlah sedimen, jumlah alat dan berapa biaya untuk pengerukan waduk sengguruh guna menormalkan fungsi waduk dan meningkatkan produksi listrik tenaga air (PLTA) ?

\section{Lokasi Studi}

Waduk Sengguruh terbentang antara $07^{\circ} 44^{\prime} 20^{\circ}$ hingga $08^{\circ} 17^{\prime} \quad 45^{\circ}$ Lintang selatan dan antara $112^{\circ} 27^{\prime} 30^{\circ}$ sampai dengan $112^{\circ} 57^{\prime} 55^{\circ}$ Bujur Timur (SubBRLKT, 1996). Secara geografis terdiri atas sub-sub DAS : Sumber Brantas, dan Lesti.

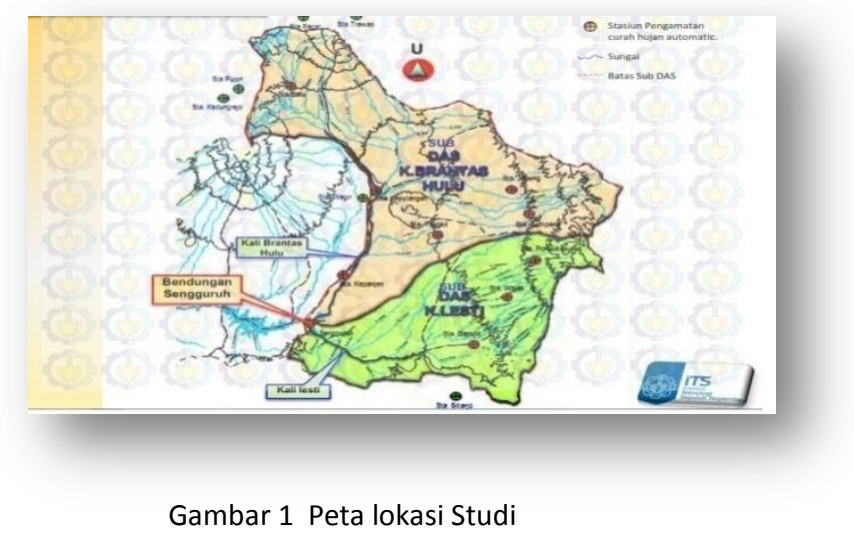

\section{Tinjauan Pustaka}

\section{Pengerukan ( Dredging )}

Pengerukan adalah mengambil tanah atau material dari lokasi didasar air, perairan dangkal seperti danau, sungai, muara ataupun laut dangkal, dan memindahkan atau membuangnya kelokasi lain.

\section{Erosi dan Sedimen}

Perubahan tata guna lahan dan praktek pengelolaan DAS juga mempengaruhi terjadinya erosi, sedimentasi, dan pada gilirannya, akan mempengaruhi kualitas air (Asdak, 1995).

\section{Tipe -Tipe Erosi}

Erosi percikan (splash erosion) adalah terlepas dan terlemparnya partikel-partikel tanah dari massa tanah akibat pukulan butiran air hujan secara langsung

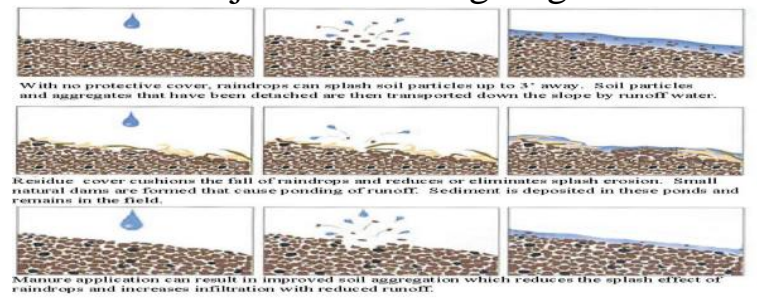

Gambar 2 Erosi percikan

Erosi aliran permukaan (overland flow erosion) akan terjadi hanya dan jika intensitas dan atau lamanya hujan melebihi kapasitas infiltrasi /kapasitas simpan air tanah 

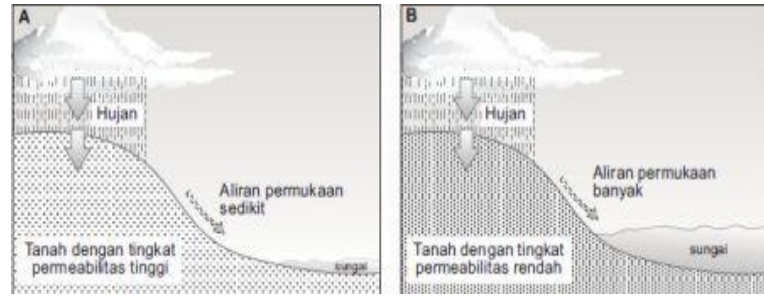

Erosi alur (rill erosion) adalah pengelupasan yang diikuti dengan pengangkutan partikel-partikel tanah oleh aliran air larian yang terkonsentrasi di dalam saluran-saluran air

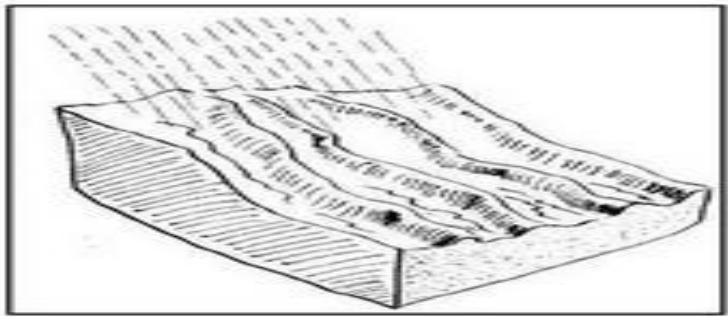

Gambar 4 Erosi alur

Erosi parit/selokan (gully erosion) membentuk jajaran parit yang lebih dalam dan lebar dan merupakan tingkat lanjutan dari erosi alur

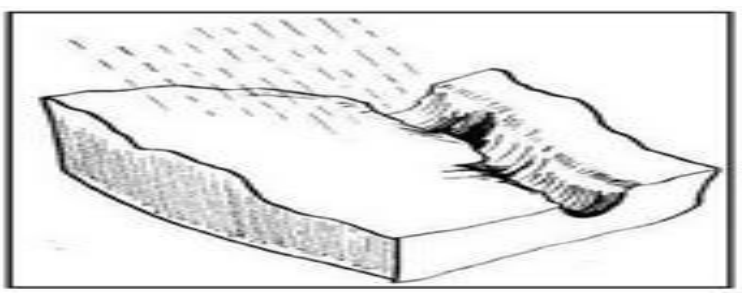

Gambar 5 Erosi Parit

\section{Erosi tebing sungai (streambank} erosion) adalah erosi yang terjadi akibat pengikisan tebing oleh air yang mengalir dari bagian atas tebing atau oleh terjangan arus sungai yang kuat terutama pada tikungan-tikungan

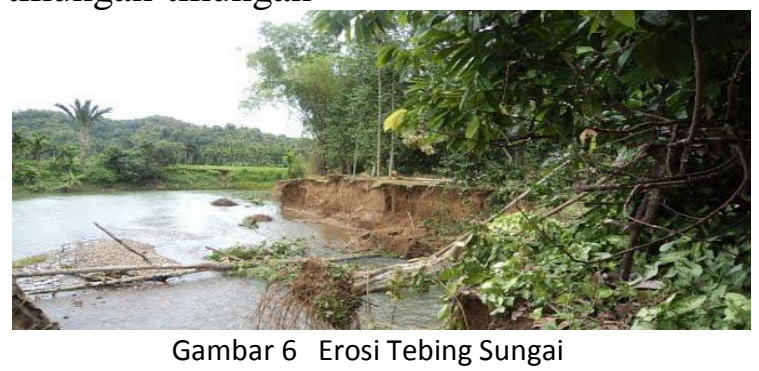

Erosi internal (internal or subsurface erosion) adalah proses terangkutnya partikel-partikel tanah ke bawah masuk ke celah-celah atau pori-pori akibat adanya aliran bawah permukaan.

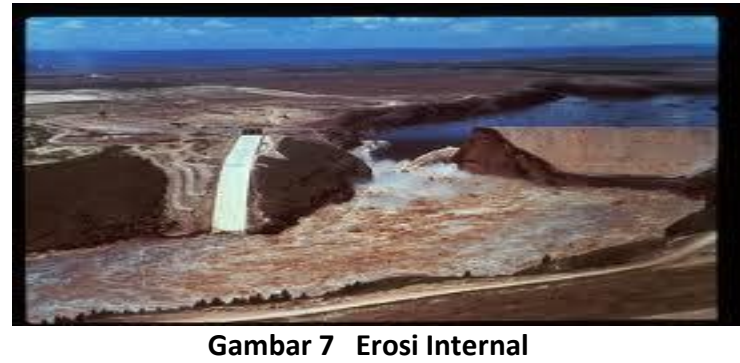

Tanah longsor (land slide) merupakan bentuk erosi dimana pengangkutan atau gerakan massa tanah yang terjadi pada suatu saat dalam volume yang relatif besar.

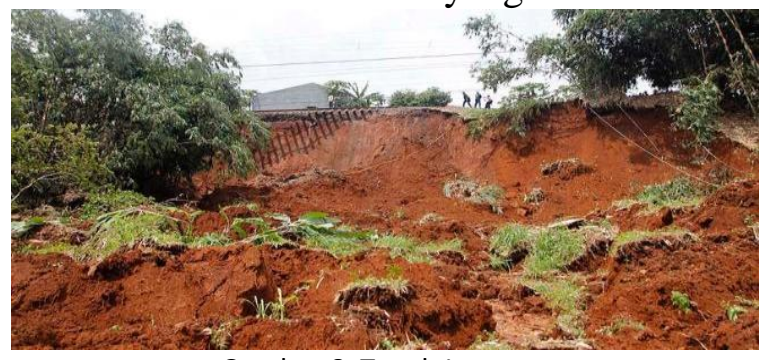

Gambar 8 Tanah Longsor

\section{Alat Berat Untuk Pembuatan Spoil}

Bank

\section{a. Swampdozer}

Alat berat yang mempunyai roda rantai (track shoe), untuk pekerjaan serba guna yang memliki kemampuan traksi yang tinggi untuk menggali, mendorong, menggusur, meratakan, menarik beban dan menimbun (Drigging, cutting/filling, pushing, spreading, grading, skidding dll).

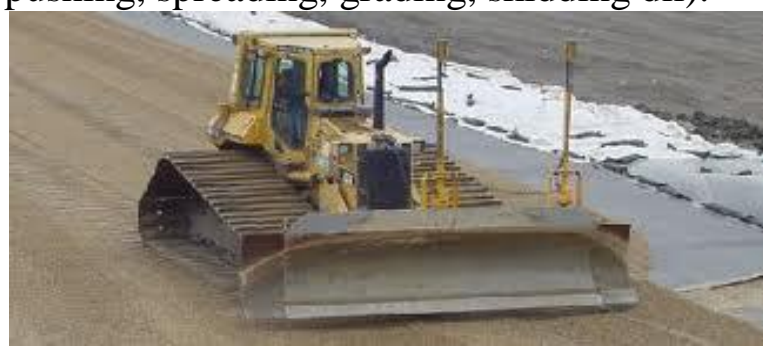

Gambar 9 Swampdozer

\section{b. Excavator}

Hydraulic excavator menggunakan tenaga, diesel engine dan full hydraulic system. Operasi excavating paling efisien adalah menggunakan metode heel dan toe (ujung dan pangkal), . 


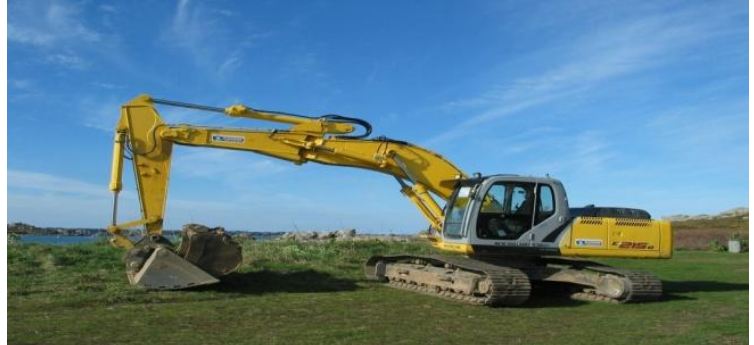

\section{c. Truck With Crane}

Truck crane dipergunakan untuk memindahkan bahan-bahan, alatalat ataupun beban di lapangan, areal pembangunan dan sebagainya. Truck crane hanya mengangkat beban-beban dalam jumlah besar dan dalam jarak yang sangat terbatas.

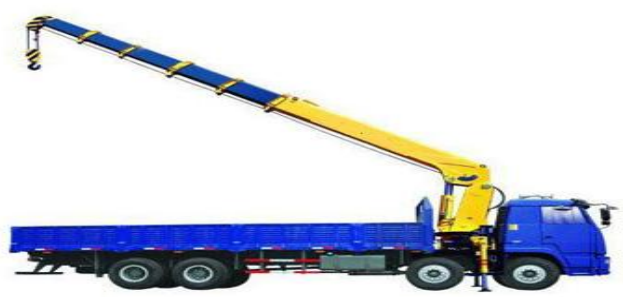

Gambar 11 Truck With Crane

\section{Jenis - Jenis Kapal Keruk}

Kapal Keruk atau dredger merupakan kapal yang memiliki peralatan khusus untuk melakukan pengerukan.

Trailing suction hopper dredger

Sebuah trailing suction hopper dredger (TSHD) menyeret pipa penghisap ketika bekerja, dan mengisi material yang diisap ke beberapa penampung (hopper) dan membuang material tersebut melalui pintu yang ada di bawah kapal ke lokasi pembuangan

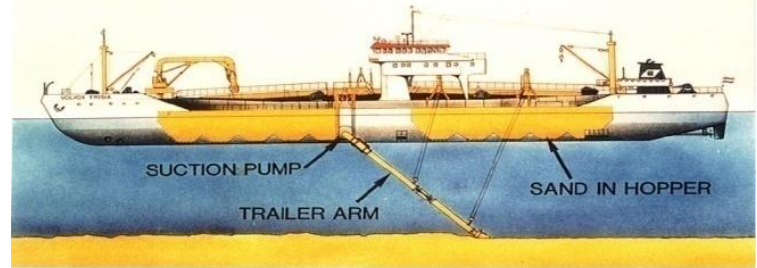

Gambar 12 Tralling Suction Hopper Dredger

\section{Cuter Suction Dredger}

Cutter-suction dredger/CSD, tabung penghisap memiliki kepala pemotong di pintu masuk penghisap.

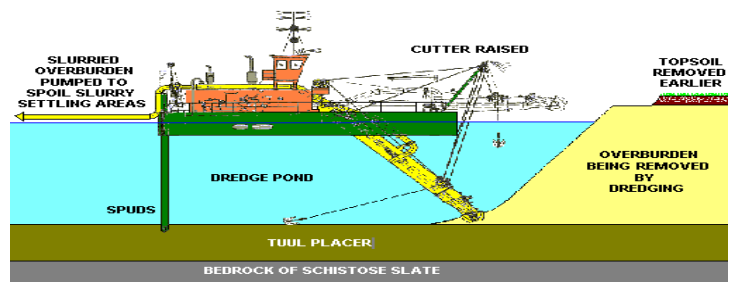

\section{Bucket Dredger}

\section{Bucket}

dredger biasanya dilengkapi dengan Bucket Wheel Dredger dan Grab dredger yang bergerak secara simultan untuk mengangkat sedimen dari dasar air.

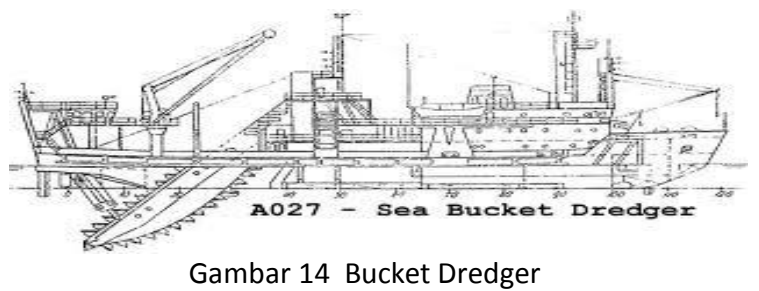

\section{Backhoe / Dipper Dredge}

\section{Backhoe/dipper dredger memiliki} sebuah backhoe seperti excavator.

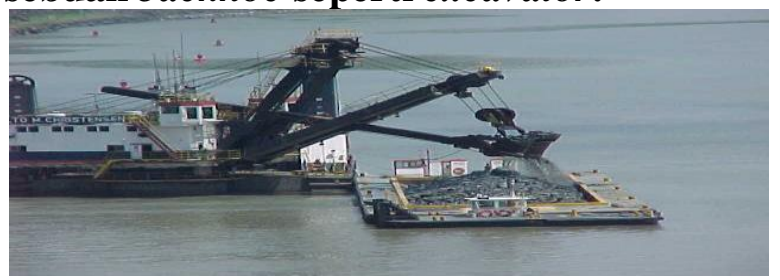

Gambar 15 Dipper Dredger

\section{Water Injection Dredger}

Water injection dredger menembakkan air di dalam sebuah jet kecil bertekanan rendah ke sedimen di dasar air agar air dapat mengikat sedimen sehingga melayang di air, selanjutnya di dorong oleh arus dan gaya berat keluar dari lokasi pengerukan.. 


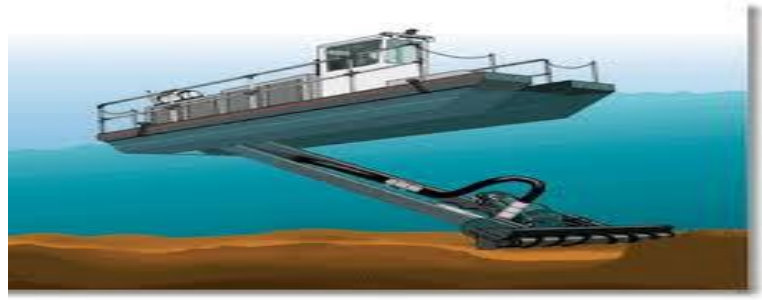

Gambar 16 watter injection dredger

\section{Metodologi Penelitian}

\section{Studi Pustaka dan Survey Lapangan Data Primer}

Wawancara dengan instansi terkait yang menangani waduk sengguruh dan peninjauan secara langsung diwaduk senguruh.

\section{Data Sekunder}

Data sedimen, data pengerukan,data PLTA Sengguruh

\section{Kapasitas Waduk}

Kapasitas Waduk Sengguruh awal dibangun direncanakan 21,5 juta $\mathrm{m}^{3}$, dengan rincian $\pm 21,5$ juta $\mathrm{m}^{3}$ sebagai volume aktif dan \pm 19 juta $\mathrm{m}^{3}$ sebagai desain volume sedimen.

\section{Sisa Umur Efektif Waduk}

Dalam menghitung umur guna Waduk dan pengoprasian Waduk sengguruh, kita harus mengetahui perhitungan Sedimen yang masuk ke waduk. Perhitungan sedimen yang masuk waduk akan menentukan besarnya tampungan mati.

Sisa umur Waduk Sengguruh dihitung melalui besarnya rata-rata masukan sedimen ke Waduk sengguruh dikurangi pengeluaran sedimen dalam satu tahun, kemudian dikalikan jumlah tahun operasi waduk sehingga diketahui volume sediment saat ini. Setelah itu hubungkan dengan rencana umur waduk yang diperkirakan ketika akan membangun waduk. Dari hasil perhitungan data-data itu kita akan memperoleh perkiraan sisa umur Waduk Sengguruh dengan mengetahui besar kapasitas volume tampungan mati Waduk Sengguruh dengan volume sedimen yang masuk ke tampungan mati Waduk Sengguruh dalam satu tahun dengan persamaan:

Perhitungan sisa umur efektip waduk sengguruh :

$$
\begin{gathered}
T w=\frac{\text { kapasitas dead stroage }(\mathrm{m} 3)}{\text { volume sedimen tahunan }(\mathrm{m} 3)} \\
\text { Keterangan : } \\
\mathrm{Tw}=\begin{array}{l}
\text { Jangka Waktu Dead Stroage penuh } \\
\text { dengan edapan sedimen }(\text { tahun })
\end{array}
\end{gathered}
$$

\section{Volume pngerukan}

Volume kerukan sedimen dihitung menggunakan data perubahan volume waduk dari tahun ke tahun.

$$
\begin{aligned}
\text { vol. } \text { sedimen } & =\frac{\text { volume sedimen }}{\Delta \text { tahun }} \\
& + \text { laju sedimen }
\end{aligned}
$$

\section{Spoil Bank}

Spoil bank ini digunakan untuk menampung hasil kerukan sedimen penentuan jumlah spoil bank dan volume spoil bank akan disesuaikan dengan volume kerukan.

$$
\text { jumlah spoilbank }=\frac{\text { volume kerukan }}{p \times l \times t}
$$

\section{Data Alat - Alat Berat}

Dari data Alat berat ini untuk menentukan jumlah alat yang dibutuhkan untuk pengerukan waduk dan alat - alat apa saja yang digunakan untuk melakukan pengerukan waduk.

\section{Kebutuhan Alat dan SDM}

Dari data alat berat kita bisa menyimpulkan kebutuhan alat apa saja yang dibutuhkan untuk pengerukan waduk dan jumlah SDM yang dibutuhkan.

\section{Analisa Data Dan Pembahasan Analisa Jumlah Alat}

Jumlah alat yang digunakan akan disesuaikan dengan data yang ada dengan perhitungan jumlah alat menggunakan rumus produksi alat berat :

Produksi Alat berat :

Rumus umum produksi alat :

$$
\mathrm{Q}=\mathrm{q} \times \frac{60}{W_{s}} \times \mathrm{E}
$$


dimana :

$\mathrm{Q}=$ produksi alat dalam satu jam (m3 /jam atau cu.yd/h)

$\mathrm{q}=$ kapasitas alat per siklus (m3 /siklus atau

cu.yd/siklus)

Ws $=$ waktu siklus (menit)

$\mathrm{E}=$ efisiensi kerja

Manentukan jumlah alat :

$$
\mathrm{N}_{1}=\frac{Q \max }{Q i}
$$

dimana $: \mathrm{n} 1=$ jumlah suatu jenis

$\mathrm{Q}_{\max }=$ produksi alat terbesar

$\mathrm{Q}_{\mathrm{i}}=$ produksi suatu jenis alat

Menentukan durasi pekerjaan :

$$
\begin{aligned}
& \mathrm{T}_{\mathrm{w}}=\frac{V}{Q \min } \\
& \text { dimana : } \mathrm{t}_{\mathrm{w}}=\text { durasi pekerjaan } \\
& \mathrm{V}=\text { volume pekerjaan } \\
& \quad \mathrm{Q}_{\min }=\text { produksi terkecil suatu alat }
\end{aligned}
$$

\section{Metode BCR (benefit cost ratio)}

BCR adalah analisis yang digunakan untuk mengevaluasi proyekproyek pemerintah sebagai cara praktis untuk menaksir kemanfaatan proyek Evaluasi dilakukan dengan menggunakan horizon perencanaan yang panjang dan melihat dan menganalisis semua efek manfaat dan ongkos

$$
B C(i)=\frac{\text { Benefit ekuivalen }}{\text { Ongkos ekuivalen }}
$$

\section{Metode NVP ( net present value )}

Metode Net Present Value (NPV) merupakan metode untuk mencari selisih antara nilai sekarang dari proceed dengan nilai sekarang dari suatu investasi.

$$
\begin{aligned}
& \text { Rumus : } \mathrm{n} \quad \text { At } \\
& \mathrm{NPV}=-\mathrm{Io}+\sum \text {----------- } \mathrm{t}=0 \quad(1+\mathrm{r}
\end{aligned}
$$$$
\text { )t }
$$

Dimana $:$ Io $=$ Nilai investasi

$$
\begin{aligned}
& \text { At }=\text { aliran kas netto pd periode } \mathrm{t} \\
& \mathrm{r}=\text { Discount rate } \\
& \mathrm{t} \quad=\text { jangka waktu proyek }
\end{aligned}
$$

investasi

Kriteria kelayakan suatu investasi :

NPV $>0$ atau positif : investasi layak dan diterima NPV $\leq 0$ atau negatif : investasi tidak layak dan ditolak

\section{Hasil dan Pembahasan \\ Analisa Jumlah Sedimen}

\begin{tabular}{|c|c|c|c|c|}
\hline Periode & $\begin{array}{l}\text { Volume } \\
\text { sedimen } \\
\left(\text { juta } m^{3} \text { ) }\right.\end{array}$ & $\begin{array}{c}\text { Perubahan } \\
\text { tampungan } \\
\text { efektif } \\
\text { ( juta m }^{3 \text { ) }}\end{array}$ & $\begin{array}{c}\text { Perubahan } \\
\text { tampungan } \\
\text { mati } \\
\left(\text { juta } \mathrm{m}^{3} \text { ) }\right.\end{array}$ & $\begin{array}{c}\text { Rata- } \\
\text { rata } \\
\text { sedimen } \\
\text { (jt m³/th) }\end{array}$ \\
\hline $\begin{array}{c}1988 \\
\text { s/d } \\
1993\end{array}$ & 16.14 & 1.29 & 14.85 & 3.23 \\
\hline $\begin{array}{c}1993 \\
\text { s/d } \\
2002 \\
\end{array}$ & 2.16 & 0.08 & 2.08 & 0.24 \\
\hline $\begin{array}{c}2002 \\
\mathrm{~s} / \mathrm{d} \\
2011 \\
\end{array}$ & 2.17 & 0.55 & 1.62 & 0.24 \\
\hline \multicolumn{4}{|c|}{ Total laju sedimen } & 3.71 \\
\hline
\end{tabular}

Dalam menganalisa jumlah sedimen yang akan dikeruk menggunakan data tampungan perubahan tampungan waduk dari tahun ke tahun, dari data ini akan didapatkan volume pengerukan sedimen/th

Tabel 1 data history tampungan waduk

\begin{tabular}{|c|c|}
\hline Tahun survei & $\begin{array}{c}\text { Volume tampungan total } \\
\left(\text { juta }^{3}\right)^{\text {jul }}\end{array}$ \\
\hline 1988 & 21.5 \\
\hline 1993 & 5.36 \\
\hline 1996 & 2.16 \\
\hline 1997 & 5.35 \\
\hline 2002 & 3.2 \\
\hline 2003 & 2.32 \\
\hline 2005 & 1.48 \\
\hline 2011 & 1.04 \\
\hline
\end{tabular}

Sumber : jasa tirta malang

Tabel 2 Rata - rata sedimen masuk waduk :

Sumber : perhitungan

Tabel 3 Laju sedimentasi tahun 2011

\begin{tabular}{|c|c|c|c|c|}
\hline waduk & periode & $\begin{array}{c}\text { Jumlah } \\
\text { tahun }\end{array}$ & $\begin{array}{c}\text { Volume } \\
\text { sedimen } \\
\left(\mathrm{jt} \mathrm{m}^{3}\right)\end{array}$ & $\begin{array}{c}\text { Rata - rata } \\
\text { sedimen } \\
\left(\mathrm{jtm}^{3} / \mathrm{th}\right)\end{array}$ \\
\hline sengguruh & $\begin{array}{c}1993 \\
\text { s/d } \\
\text { 2011 }\end{array}$ & 18 & 4.323 .000 & 240.000 \\
& & & \\
\hline \multicolumn{6}{|c|}{ Total laju sedimen } & 240.000 \\
\hline
\end{tabular}

Laju sedimen $/$ thn $=4.323 / 18=240.000$ $\mathrm{m}^{3}$

Jumlah sedimen /th yang harus dikeruk: 
$\frac{\text { volume sedimen }}{\Delta \text { tahun }}+$

laju sedimen pertaHun

$$
=\left(\frac{4.323 .000}{20}\right)+240.000
$$$$
=456.150 \mathrm{~m}^{3} / \text { tahun }
$$

Pengerukan akan dilaksanakan jangka panjang selama 20 tahun.

\section{Rencana pengerukan}

Pengerukan akan dilaksanakan jangka panjang dari tahun 2013 sampai 2033 selama 20 tahun, selama pengerukan jangka panjang dihulu waduk sengguruh akan dibangun pengendali sedimen, dan konservasi lahan agar mengurangi sedimen yang masuk ke waduk sengguruh.

\section{Analisa Alat Berat dan Biaya}

Alat - alat yang digunakan untuk pengerukan selama 1 tahun dengan volume keruk $456.150 \mathrm{~m}^{3}$, menggunakan alat alat berat berupa excavator, kapal keruk, swampdozer, truck dan alat - alat penunjang lainnya, adapun perhitungan alatnya akan dihitung sesuai dengan volume yang dikeruk selama 1 tahun penuh.

\section{Water injection Dredger}

Kapal keruk jenis water injection dredger kapasitas kompa $150 \mathrm{mch}$

$$
\mathrm{Q}=\mathrm{A} \times \mathrm{V}=1 / 4 \pi \cdot \mathrm{D}^{2} . \mathrm{V}
$$$$
=1 / 4 \times 3,14 \times 0,61^{2} \times 3=0,876 \mathrm{M}^{3} / \text { detik }
$$

Tenaga pompa $=(150$.W.Q.H) $/(75 . n)$

$$
=(150 \times 1,4 \times 0,876 \times 15,68) /(75 \times n
$$

)

$=200 \mathrm{hp}$

Kapasitas pengerukan / jam :

$\mathrm{Q}=0,876 \times 3600=3.121,2 \mathrm{~m}^{3}$ sediment Perhitungan pengerukan / tahun Volume keruk $=3121.2 \times 8 \times 12=299635,2 \mathrm{~m}^{3} /$ unit

Kapal keruk yang digunakan untuk mengeruk waduk sengguruh adalah kapal keruk ellicot yang panjang kapal $8 \mathrm{~m}$, dan lebar kapal 4 m, daya keruk kapal 150 mch, daya mesin $1500 \mathrm{hp}$, sewa alat Rp.300.000/jam (Sumber: Tarip dasar sewa peralatan berdasarkan keputusan direksi Perum Jasa Tirta 1 nomor KP.103/KPTS.DA.2004 Tanggal $31 \mathrm{Mei}$
2004 ) kapal keruk jenis ini cocok untuk pengerukan diwaduk sengguruh dengan keadaaan dan medan yang sulit.

Jika pengerukan selama setahun menggunakan 4 unit kapal keruk mangka setiap unit kapal keruk = sewa alat perjam x 8 jam x jumlah hari selama 1 tahun $:=300.000 \times 8$ × $365=$ Rp. 876.000 .000

Untuk sewa kapal keruk 1 units selama 1 tahun membutuh dana sebesar Rp.876.000.000, dan bila setiap units kapal keruk biaya sewa Rp 876.000.000 dan untuk mengeruk sedimen sebesar 456.150 $\mathrm{m}^{3} /$ tahun maka Rp.876.000.000 x 2 units $=$

Rp. 1.752 .000 .000

\section{Excavator}

Excavator merek komatsu kapasitas mud bucket $0,8 \mathrm{~m}^{3}$

$\rightarrow$ Produksi per cyle (q)

$\mathrm{q}=\mathrm{q} 1 \times \mathrm{K}$

$\mathrm{q}=0,8 \times 1,2=0,96 \mathrm{~m}^{3}$

cycle time $(\mathrm{cm})=80 \times 0,9=72$

$\rightarrow$ Job efficiency ( $\mathrm{E}$ )

$\mathrm{Q}=\mathrm{q} \times 3600 \times \mathrm{xE} / \mathrm{CM}$

$\mathrm{Q}=0,96 \times 3600 \times 0,83 / 72$

$\mathrm{Q}=39,84 \mathrm{~m}^{3} / \mathrm{jam}$

Satu buah excavator merk komatsu kapasitas bucket $0,8 \mathrm{~m}^{3}$ akan mampu mengeruk tanah $39,80 \mathrm{~m}^{3} /$ jam (biaya sewa alat Rp.120.000/jam) .bila digunakan setahun

$=120.000 \times 8$ jam $\times 365=$ Rp. 350.400 .000

\section{Swampdozer}

$\rightarrow$ Produksi per cyle (q)

$$
\mathrm{q}=\mathrm{q} 1 \times \mathrm{K}
$$$$
\mathrm{q}=13 \times 1,2=15,6 \mathrm{~m}^{3}
$$

cycle time $(\mathrm{cm})=80 \times 0,9=72$

$\rightarrow$ Job efficiency ( $\mathrm{E})$

$\mathrm{Q}=\mathrm{qx} 3600 \times \mathrm{xE} / \mathrm{CM}$

$\mathrm{Q}=15,6 \times 3600 \times 0,83 / 72=624 \mathrm{~m}^{3} /$ jam

Perhitungan produktivitas sebuah bulldozer saat melakukan dozing / excavating operation adalah $624 \mathrm{~m}^{3 /}$ jam, Swampdozzer yang digunakan adalah 
merk komatsu yang punya daya dorong 13 ton, dan biaya sewa Rp.100.000/jam. Bila digunakan setahun $=100.000 \times 8 \times 365=$ Rp.292.000.000 / unit.

\section{Dump Truck}

Jumlah tanah yang dipindahkan :

$=100.000 / 0,8=125.000$

Menghitung waktu pengangkutan :

Berat $=$ berat kosong + (heaped capacity $\mathrm{x}$ bj tanah ) < berat maksimum

$$
\begin{aligned}
& =39396+(29 \times 1300) \\
& =77096 \mathrm{~kg}<92534 \mathrm{~kg}
\end{aligned}
$$

Berat truck $=39396 \mathrm{~kg}$

Waktu siklus $=\mathrm{t} 1+\mathrm{t} 2+\mathrm{t} 3+\mathrm{t} 4$

$=3+85,46+1,50+46,18=136,14$

Produktivitas truck $=$ kapasitas $\mathrm{x} 60 /$ ct $\mathrm{x}$ job efficiency

$=29 \times 60 / 136,14 \times 45 / 60=9,591 \mathrm{~cm}$ /jam

Jumlah truck $=39,84 / 9,59=4,5 \sim 5$ truck

Dump truck yang digunakan adalah merk isuzu yang mempunya kapasitas 6 ton, dengan biaya sewa per-jam Rp.20.000 x 5 units $=$ Rp. $250.000 /$ jam dan bila digunakan selama 1 tahun maka biaya sewa $=$ Rp. $250.000 .000 \times 8$ jam $\times 365$ hari $=$ Rp.730.000.000

\section{Kesimpulan dan Saran Kesimpulan}

1. Jumlah sedimen yang harus dikeruk untuk menormalkan produksi PLTA sengguruh $456.150 \mathrm{~m}^{3} /$ tahun.

2. Dalam pelaksanaan pengerukan jumlah alat - alat yang digunakan berjumlah 11 unit, dengan rincian 4 unit kapal keruk, 5 unit dump truck, 1 unit excavator dan 1 unit swampdozer.

3. Untuk pelaksanaan pengerukan waduk sengguruh biaya yang dibutuhkan selama 1 tahun berjumlah Rp. 7.499.150.000 dan jika pelaksanaan pengerukan selama 20 tahun maka jumlah biaya keseluruhan dari pelaksanaan pengerukan ini adalah Rp.195.471.938.880.

4. Dari perhitungan sedimen waduk, pengerukan sengguruh bisa dilaksanakan selama 10 tahun, karena sudah bisa memaksimalkan kegiatan normalisasi hingga mencapai 21.500.000 $\mathrm{m}^{3}$ sehingga dapat berfungsi kembali sesuai rencana tampungan total waduk.

5. Berdasarkan daya listrik setelah pengerukan dibandingkan dengan daya listrik yang dihasilkan PLTA Sengguruh saat ini $29.000 \mathrm{KW}$ saat musim hujan dan $14.000 \mathrm{KW}$ saat musim kering, sehingga terjadi peningkatan daya listrik setelah pengerukan.

\section{Saran}

Agar kegiatan pengerukan lebih ekonomis diupayakan sebagian volume sedimen dapat ditahan dialur sungai dengan memanfaatkan pengendali sedimen ( sabo, chek dam ) dan memanfaatkan aktifitas penambang pasir sepanjang kali lesti, sedangkan sedimen yang berasal dari kali berantas hulu harus direduksi dengan konservasi lahan baik secara vegetatif maupun mekanis. Namum mengingat fungsi utama waduk sengguruh sebagai pengontrol sedimen yang akan masuk waduk sutami, maka perlu kajian lebih lanjut. hal ini terkait dengan analisa ekonomi dan fungsi waduk sutami.

\section{Daftar Pustaka}

Azdan, M.D., \& Samekto, C.R. 2008. "Kritisnya Kondisi Bendungan di Indonesia" Seminar Komite Nasional Indonesia untuk Bendungan Besar (KNI-BB). Surabaya- Indonesia.

Pratam yudo sezar .2010."Studi Optimasi Operasional Waduk Sengguruh untuk Pembangkit Listrik Tenaga Air'jurusan teknik Sipil FakultasTeknik Sipil dan Perencanaan Institut Teknologi Sepuluh Nopember Surabaya.

Suyanto A., Sunaryo T., Sjarief R. 2001. Ekonomi Teknik Proyek Sumberdaya Air. Penerbit Masyarakat Hidrologi 
Suroso, M. Ruslin Anwar dan Mohammad Candra Rahmanto.2012. "studi pengaruh sedimentasi kali berantas terhadap kapasitas dan usia rencana waduk sutami malang” Jurusan Sipil Fakultas Teknik Universitas Brawijaya Malang.
Viari Djajasinga, Aniek Masrevaniah, Pitojo Tri Juwono. 2012. "kajian ekonomi penangganan sedimen pada waduk seri disungai beratas ( sengguruh, sutami dan wlingi)" Mahasiswa Program Magister Teknik Pengairan Universitas Brawijaya Malang 